\title{
Reductive dechlorination of trichloroethylene (TCE) in competition with Fe and Mn oxides - observed dynamics in H2-dependent terminal electron accepting processes
}

Paul, Laiby; Jakobsen, Rasmus; Smolders, Erik; Albrechtsen, Hans-Jørgen; Bjerg, Poul Løgstrup

Published in:

Geomicrobiology Journal

Link to article, DOI:

$10.1080 / 01490451.2015 .1043410$

Publication date:

2016

Document Version

Peer reviewed version

Link back to DTU Orbit

Citation (APA):

Paul, L., Jakobsen, R., Smolders, E., Albrechtsen, H-J., \& Bjerg, P. L. (2016). Reductive dechlorination of trichloroethylene (TCE) in competition with $\mathrm{Fe}$ and $\mathrm{Mn}$ oxides - observed dynamics in $\mathrm{H} 2$-dependent terminal electron accepting processes. Geomicrobiology Journal, 33(5), 357-366.

https://doi.org/10.1080/01490451.2015.1043410

\section{General rights}

Copyright and moral rights for the publications made accessible in the public portal are retained by the authors and/or other copyright owners and it is a condition of accessing publications that users recognise and abide by the legal requirements associated with these rights.

- Users may download and print one copy of any publication from the public portal for the purpose of private study or research.

- You may not further distribute the material or use it for any profit-making activity or commercial gain

- You may freely distribute the URL identifying the publication in the public portal 
Reductive dechlorination of trichloroethylene (TCE) in competition with Fe and Mn oxides - observed dynamics in $\mathrm{H}_{2}$-dependent terminal electron accepting processes Laiby Paul $^{1}$, Rasmus Jakobsen ${ }^{3}$, Erik Smolders ${ }^{1}$, Hans-Jørgen Albrechtsen ${ }^{2}$, Poul L. Bjerg ${ }^{2} *$

${ }^{1}$ Division of Soil and Water Management, KU Leuven, Kasteelpark Arenberg, B-3000 Leuven, Belgium

${ }^{2}$ Department of Environmental Engineering, Miljoevej, Building 113, Technical University of Denmark, DK-2800 Lyngby, Denmark

${ }^{3}$ Geochemical Department, GEUS, Øster Voldgade 10, 1350 Copenhagen K, Denmark

*Correspondence to: Poul L. Bjerg, Department of Environmental Science and Engineering, Miljoevej, Building 113, Technical University of Denmark, DK-2800, Lyngby, Denmark; Phone: +45 452516 15; Fax: +45 45932850 Email: plb@env.dtu.dk

\begin{abstract}
The determination of hydrogen $\left(\mathrm{H}_{2}\right)$ concentration together with the products of microbial reduction reactions in a trichloroethylene dechlorinating system is conducted to delineate the ongoing predominant terminal electron accepting processes (TEAP). Formate was used as electron donor and synthetic Fe minerals or environmental samples were used as the substrata. Iron(III) and $\mathrm{Mn}(\mathrm{IV})$ reduction limited microbial dechlorination by the mixed anaerobic culture by decreasing the level of $\mathrm{H}_{2}$ in the system. The $\mathrm{H}_{2}$ measurements indicated that the $\mathrm{H}_{2}$ concentration at which different TEAPs occur can overlap and thus these TEAPs can therefore occur concurrently rather than exclusively. Difference in Fe(III) bioavailability and hence, $\mathrm{Fe}(\mathrm{III})$ reduction partially explain this wide range. The distinction between dechlorination and other microbial reduction processes based on $\mathrm{H}_{2}$ threshold values is not feasible under such conditions, though there appears to be a relation between the rates of $\mathrm{H}_{2}$ consuming process and the observed $\mathrm{H}_{2}$ level.
\end{abstract}

Keywords: Trichloroethylene, Fe reduction, Reductive dechlorination, Manganese reduction, Hydrogen concentration.

Brief: Hydrogen determination in a laboratory batch system under different redox conditions have been used to assess dynamics of reductive dechlorination 


\section{Introduction}

Trichloroethylene (TCE), a chlorinated hydrocarbon compound, has been widely used for metal cleaning and degreasing industries in the past and is frequently detected as a groundwater contaminant. Microbial transformation of TCE into cis-dichloroethylene (cisDCE) and vinyl chloride (VC) and finally into the environmentally benign product ethene occurs in anaerobic environments and is termed reductive dechlorination (Bradley, 2003; Maymo-Gatell et al., 1997). Different organic compounds can undergo fermentation reactions and produce $\mathrm{H}_{2}$ or can directly serve as electron donor for TCE dechlorination. The efficacy of microbial reductive dechlorination in anaerobic environments is determined by various factors such as the presence of specific dechlorinating microorganisms, availability of solid and aqueous electron acceptors as well as electron donor and the actual chlorinated ethenes present (Chambon et al., 2013).

The dechlorination reaction depends on the hydrogen $\left(\mathrm{H}_{2}\right)$ concentration present in the system and different terminal electron accepting processes (TEAP) tend to occur at different $\mathrm{H}_{2}$ concentrations. Hydrogen threshold concentrations for different metabolic processes reported in previous experimental studies under a range of conditions are $<0.1 \mathrm{nM}$ for nitrate reduction; < $0.5 \mathrm{nM}$ for $\mathrm{Mn}(\mathrm{IV})$ reduction; 0.1-0.8 $\mathrm{nM}$ during iron(III) reduction; 0.6-0.9 nM for TCE reduction, 0.1-2.5 nM for cis-DCE reduction and 2-24 nM for VC reduction; 1-15 $\mathrm{nM} \mathrm{H}_{2}$ for sulfate reduction, 5-100 nM and > $354 \mathrm{nM}$ during methanogenesis and acetogenesis, respectively (Heimann et al., 2009; Löffler et al., 1999; Lovley and Goodwin, 1988; Lu et al., 2001; Luijten et al., 2004; Mazur et al., 2003; Yang and McCarty, 1998). These $\mathrm{H}_{2}$ ranges suggest that TCE reduction may take place along with $\mathrm{Fe}$ (III) reduction followed by sulfate reduction. Sulfate and Fe(III) present in the aquifer indeed have a detrimental effect on the success of reductive dechlorination of TCE, since it may stall at DCE or VC as final products. Thus the dechlorinators may have to compete for the available electron equivalents with these alternate terminal electron accepting processes such as $\mathrm{Fe}$ (III) and sulfate reduction. It should be noted that these threshold concentrations should be applied for situations of limited electron donors. Hoehler et al. (1998) suggested that for some processes, the $\mathrm{H}_{2}$ concentration is influenced by the environmental conditions such as reactant and product concentrations as well as temperature and $\mathrm{pH}$ conditions i.e., the thermodynamics of the processes. The partial equilibrium approach states that the fermentation reaction determines the overall rate while TEAPs are close to their equilibrium. This approach explains the $\mathrm{H}_{2}$ concentration in natural systems and the occurrence of concomitant TEAPs (Jakobsen et al., 1998; Postma and Jakobsen, 1996).

It has been shown that reductive dechlorination of TCE does occur under Fe(III) reducing conditions (Azizian et al., 2008; Paul et al., 2013; Wei and Finneran, 2011) while a few other studies indicate that concomitant $\mathrm{Fe}$ (III)-reduction poses a competitive inhibition to the dechlorination process, especially on cis-DCE and VC dechlorination (Dupont et al., 2003; Evans and Koenigsberg, 2001; Paul et al., 2013; Yager et al., 1997). Different approaches have been used to assess the redox conditions during transformation of TCE such as the concentration of either the parent compound or electron donor or of reduced species such as $\mathrm{Fe}^{2+}, \mathrm{HS}^{-}$and $\mathrm{CH}_{4}$ (Damgaard et al., 2013; Hunkeler et al., 2011). As described above, $\mathrm{H}_{2}$ concentrations can also be used as an indicator of the dominant TEAP in natural or contaminated groundwater systems (Chapelle et al., 1996; Lovley and Goodwin, 1988).

From our previous study using different synthetic Fe minerals, it has been shown that the competition between TCE reduction and Fe reduction is influenced by Fe mineralogy (Paul et al., 2013). In that study, the characteristic $\mathrm{H}_{2}$ concentration at which both processes are occurring have not been measured. Such measurements, combined with a detection of 
dechlorination rate, formate oxidation and iron reduction processes, can lead to a better prediction of ongoing TEAPs and requirements of electron equivalents. The objective of this study is to determine critical $\mathrm{H}_{2}$ concentrations at which TCE reduction and $\mathrm{Fe}$ (III) reduction reaction occurs depending on iron mineralogy. We have used synthetic Fe minerals as well as subsurface materials or subsoils containing natural Fe oxides; the TCE dechlorination was measured in a controlled system by using a constant medium composition and an initially identical microbial inoculum.

\section{Materials and methods}

\subsection{Experimental set up}

\subsubsection{Chemicals:}

The following chemicals were purchased in liquid form: trichloroethylene (GC grade 99.5 $\pm \%$,) and cis-dichloroethene (97\%, Acros).Vinyl chloride was purchased from Gerling, Holz \& Co. (99.97\%), and ethene was obtained as pure gas from Mikrolab, Aarhus. Formate as a sodium salt (Sigma Chemical Company, USA; 99\% purity) was used as the sole added electron donor.

\subsubsection{Samples and Fe characterization}

The synthetic iron(III) oxide phases used in this study (Table 1) included a 2-line ferrihydrite suspension (HFO), 2-line ferrihydrite powder, 6-line ferrihydrite powder, goethite and lepidocrocite. These were synthesized according to Schwertmann and Cornell (2000) and coated or mixed on to fine quartz sand $(>125 \mathrm{~mm}, 0.0 \%$ organic matter) to have a final total $\mathrm{Fe}(\mathrm{III})$ concentration as given in Table 1 .

The sand contained a background Fe concentration of $0.90 \mathrm{mmol} \mathrm{Fe} \mathrm{kg}^{-1}$ sand. Two-line ferrihydrite suspension, 2-line ferrihydrite powder and 6-line ferrihydrite were directly mixed to the sand while goethite and lepidocrocite were coated onto the sand according to Paul et al. (2013). 
Table 1. Characteristics of synthetic Fe(III) oxides coated sand and natural subsurface materials used in microbial and chemical reduction experiments. Mean values of replicates.

\begin{tabular}{|c|c|c|c|c|c|c|c|c|c|}
\hline \multirow{3}{*}{ Material } & \multicolumn{3}{|c|}{ Before anaerobic incubation } & \multicolumn{6}{|c|}{ After 50 days of anaerobic incubation } \\
\hline & Total $\mathrm{Fe}^{\mathrm{a}}$ & $\begin{array}{c}\text { 5N HCl- } \\
\text { Ext } \\
\mathrm{Fe} \text { (III) }\end{array}$ & $\begin{array}{c}\text { 5N HCl-Ext } \\
\text { Mn(IV) }\end{array}$ & $\begin{array}{c}5 \text { N HCl-Ext } \\
{[\mathrm{Fe}(\mathrm{II})+} \\
\mathrm{Fe}(\mathrm{III})]\end{array}$ & $\begin{array}{l}\text { 5N HCl- } \\
\text { Ext Fe(II) }\end{array}$ & $\begin{array}{l}0.5 \mathrm{~N} \\
\mathrm{HCl}-\mathrm{Ext} \\
{[\mathrm{Fe}(\mathrm{II})+} \\
\mathrm{Fe}(\mathrm{III})]\end{array}$ & $\begin{array}{l}0.5 \mathrm{~N} \mathrm{HCl}- \\
\text { Ext } \mathrm{Fe}(\mathrm{II})^{b}\end{array}$ & $\begin{array}{l}\text { 5N HCl- } \\
\text { Ext Mn }\end{array}$ & $\begin{array}{c}0.5 \mathrm{~N} \mathrm{HCl}- \\
\text { Ext } \mathrm{Mn}\end{array}$ \\
\hline & $\mathrm{mmol} \mathrm{kg}{ }^{-1}$ & $\begin{array}{l}\% \text { of } \\
\text { total Fe }\end{array}$ & $\mathrm{mmol} \mathrm{kg}{ }^{-1}$ & & $\%$ of tot & al Fe & & $\%$ of $5 \mathrm{~N}$ & ICl-Ext Mn \\
\hline No Fe & 0.9 & 16 & N.D & 16 & 4 & 8 & 10 & N.D & N.D \\
\hline $\begin{array}{l}\text { 2-line ferrihydrite } \\
\text { suspension(HFO) }\end{array}$ & 44.6 & 101 & N.D & 70 & 9 & 35 & 6 & N.D & N.D \\
\hline $\begin{array}{l}\text { 2-line } \\
\text { ferrihydrite }\end{array}$ & 26.0 & 100 & N.D & 69 & 4 & 44 & 5 & N.D & N.D \\
\hline 6-line ferrihydrite & 26.0 & 100 & N.D & 70 & 6 & 35 & 7 & N.D & N.D \\
\hline Lepidocrocite & 32.2 & 98 & N.D & 72 & 1 & 38 & 3 & N.D & N.D \\
\hline Goethite & 31.8 & 100 & N.D & 73 & 1 & 2 & 1 & N.D & N.D \\
\hline Vejen & 103.2 & 67 & 3.8 & 53 & 6 & 11 & 5 & 76 & 37 \\
\hline Grindsted & 271.4 & 62 & 1.4 & 35 & 5 & 16 & 4 & 64 & 86 \\
\hline Farum & 70.4 & 66 & 1.4 & 43 & 2 & 11 & 3 & 86 & 57 \\
\hline Vadsbyvej & 229.2 & 79 & 8.9 & 69 & 4 & 0.3 & 0.2 & 58 & 21 \\
\hline
\end{tabular}

a determined using aqua-regia digestion ( $\mathrm{n}=2) ; 5 \mathrm{~N} \mathrm{HCl}, 72 \mathrm{hr}$ extraction, mean ( $\mathrm{n}=3) ; 0.5 \mathrm{~N} \mathrm{HCl}, 1 \mathrm{hr}$ extraction, mean ( $\mathrm{n}=3$ ); ${ }^{\mathrm{b}}$ adsorbed Fe(II) extracted at the end of experiment using acid extraction and analyzed by ferrozine assay; mean (n=3); N.D- not determined.

The sand contained a background Fe concentration of $0.90 \mathrm{mmol} \mathrm{Fe} \mathrm{kg}^{-1}$ sand. Two-line ferrihydrite suspension, 2-line ferrihydrite powder and 6-line ferrihydrite were directly mixed to the sand while goethite and lepidocrocite were coated onto the sand according to Paul et al. (2013). The specific surface area of HFO, 2-line ferrihydrite powder, 6-line ferrihydrite powder, lepidocrocite and goethite was 250, 214, 209, 61 and $37 \mathrm{~m}^{2} \mathrm{~g}^{-1}$, respectively as determined by multipoint BET (Brunauer, Emmett and Teller) analysis (Paul e al., 2013). The solubility of these iron oxides was also determined by acidic oxalate solution extraction at room temperature in dark condition for $2 \mathrm{~h}$ at a solid: liquid ratio (S:L) of 1:50. The poorly crystalline iron oxide, HFO was completely dissolved in the solution while around half of the powder ferrihydrite forms (53\% and 51\% for 2-line and 6-line ferrihydrite, respectively) were dissolved in oxalate solution. Lepidocrocite was dissolved up to $62 \%$ of the total amount added while the crystalline oxide, goethite was dissolved only up to $4 \%$.

The sediment samples were homogenized prior to the addition to the bottles. Four previously characterized Fe(III) bearing subsurface materials from well described Danish field sites such as Grindsted (Heron et al., 1998),Vejen (Bjerg and Christensen, 1992; Heron et al., 1994; Pedersen et al., 1991), Farum (Andersen and Vikjær Lassen, 1990) and Vadsbyvej (Damgaard et al., 2013) were also included. It has been shown in previous studies that the predominant terminal electron acceptors at the sampling location in the Grindsted landfill leachate plume were $\mathrm{Fe}(\mathrm{III})$, and in addition Mn reduction also appears to be taking place in more oxidized parts of the plume (Albrechtsen et al., 1999; Bjerg et al., 1995). At Vadsbyvej $\mathrm{Fe}$ (III)-reduction was the prevailing redox process (Damgaard et al., 2013), while the redox conditions at Vejen and Farum were aerobic (Andersen and Vikjær Lassen, 1990; Pedersen et al., 1991). The sediment samples used were dry samples stored for several years to months at room temperature prior to incubation.

Total sediment contents of $\mathrm{Fe}$ and $\mathrm{Mn}$ were determined for the synthetic $\mathrm{Fe}(\mathrm{III})$ oxide and natural sediment samples by boiling aqua regia extraction $\left(\mathrm{HNO}_{3}: \mathrm{HCl}, 1: 3\right)$ for $4 \mathrm{~h}$ at $140{ }^{\circ} \mathrm{C}$ 
and $5 \mathrm{~N} \mathrm{HCl}$ extraction. In addition, the reduced $\mathrm{Fe}$ fraction (before and after microbial incubation) was determined by anaerobic acid extractions using $1 \mathrm{~g}$ subsamples of synthetic and environmental samples in $10 \mathrm{~mL}$ of extractants i.e., $0.5 \mathrm{~N} \mathrm{HCl}$ extractions for $1 \mathrm{~h}$ and $5 \mathrm{~N}$ $\mathrm{HCl}$ extractions for $72 \mathrm{~h}$ in parallel at room temperature and at $30 \mathrm{rpm}$ (Heron et al., 1994) and followed by a ferrozine assay (Viollier et al., 2000). The concentration of Fe(III) extracted by $5 \mathrm{~N} \mathrm{HCl}$ and aqua regia digestion were very similar (Table 1) for the synthetic $\mathrm{Fe}$ oxides. The $5 \mathrm{~N} \mathrm{HCl}$ extraction constituted only $60-80 \%$ of total $\mathrm{Fe}$ content (determined by aqua regia extraction) in environmental samples implying that $5 \mathrm{~N} \mathrm{HCl}$ extraction cannot be used as a total Fe extraction method. The sediment samples from Grindsted and Vadsbyvej contained the highest quantities of Fe. The results of chemical extraction (Table 1) shows the presence of $\mathrm{Fe}$ (III) as well as a considerable amount of Mn and consequently both can act as terminal electron acceptors along with TCE.

\subsection{Laboratory batch experiment}

The synthetic and environmental samples ( $28 \mathrm{~g}$ dry weight ) were suspended in $20 \mathrm{~mL}$ of sterile anaerobic MOPS buffered $(10 \mathrm{mM}, \mathrm{pH} 7.2)$ anaerobic medium (details given in supplementary information) contained in $118 \mathrm{~mL}$ serum bottles (Wheaton Industries, Millville, NJ). Besides the sterile media, inoculation and sampling were conducted by using sterile syringes and needles. However, ferric iron oxides and $\mathrm{Fe}$ oxides containing environmental samples were not sterilized since heat and pressure during autoclaving might induce changes in crystallinity, particle size and surface area of the Fe oxides. Control sand was also not sterilized in order to treat it in the same way as the other solid substrata. All the anaerobic experimental bottles were prepared outside the anaerobic chamber using a $\mathrm{N}_{2}$ flushing system in order to prevent contamination by $\mathrm{H}_{2}$ from the anaerobic chamber where a $5 \% \mathrm{H}_{2}$ gas is used. Resazurin served as the redox indicator. Sodium formate was used as the electron donor and was added to a final concentration of $9 \mathrm{mM}$, implying an excess electron equivalents compared to the stoichiometric amount required for the complete reduction of TCE. After the addition of formate, the bottles were incubated for 19 days (indicated as negative days in figures) to create anaerobic reducing conditions conducive for the reductive dechlorination process. After this pre-incubation period, TCE was subsequently added from a $7.6 \mathrm{mM}$ stock solution of TCE prepared in the anaerobic mineral medium in an amount resulting in a calculated aqueous concentration of $1 \mathrm{mM}$, taking into account the amount that will enter into the headspace using the dimensionless Henry constant reported by Gossett (1987). The batch bottles were then amended with $5 \%(\mathrm{v} / \mathrm{v})$ of the KB-1 consortium (see below). Each batch experiment consisted of four replicates and included a biotic control without any added iron content and a sterile (abiotic) control treatment (no Fe added) amended with $1 \%$ formaldehyde to inhibit microbial activity. Changes in the concentration of chlorinated ethenes due to repetitive headspace sampling were adjusted for using the relative concentration changes in the abiotic control assumed to be related to the sampling (e.g. if $2 \%$ TCE was removed by a sampling of the abiotic control, measured amounts in the other bottles were divided by 0.98 for the corresponding sample event. Because the correction is made for the specific sample events, errors introduced due to varying concentrations and the slow degradation in the abiotic control are minor. Soluble $\mathrm{Fe}^{2+}$ was monitored over time from the liquid phase throughout the degradation experiment using the ferrozine assay (Viollier et al., 2000) and this measurements were used to calculate the rate of aqueous $\mathrm{Fe}(\mathrm{II})\left(\mathrm{Fe}(\mathrm{II})_{\mathrm{aq}}\right)$ production later. The relative percentage of $\mathrm{Fe}(\mathrm{II})_{\mathrm{aq}}$ of $\mathrm{Fe}(\mathrm{II})_{\mathrm{tot}}$ in synthetic $\mathrm{Fe}$ oxide experiments were around $27 \%$ in 2-line and 6-line ferrihydrites, $24 \%$ in lepidocrocite and 21 and $10 \%$, respectively for HFO and geothite. In environmental samples, the percentage of $\mathrm{Fe}(\mathrm{II})$ aq of the total $\mathrm{Fe}$ (II) produced was very low compared to the synthetic Fe oxides (4\%, 
$7 \%$ and $8 \%$ in Vejen, Grindsted and Farum, respectively) except in the case of Vadbyvej (19\%). The determination of sediment bound Fe(II) over time from the batch bottles was virtually impossible due to the strict anaerobic condition requirement of the experiments as well as the volatile nature of chlorinated ethenes leading them to escape from the bottle even it is opened inside the glove box. However, since the concentration of dissolved $\mathrm{Fe}$ is generally increasing it is assumed that the amount of $\mathrm{Fe}(\mathrm{II})$ precipitating must be limited. To quantify the total amount of $\mathrm{Fe}$ (II) produced, anaerobic $0.5 \mathrm{~N} \mathrm{HCl}$ (Lovley and Phillips, 1986) and $5 \mathrm{~N} \mathrm{HCl}$ extractions were performed on the reduced sand after ending the batch experiments. The supernatant was decanted, filtered and measured by ferrozine assay for $\mathrm{Fe}^{2+}$ and for total $\mathrm{Fe}$ and $\mathrm{Mn}$ (assumed to be dissolved $\mathrm{Mn}$ (II)) by atomic absorption spectroscopy.

\subsection{Anaerobic dechlorinating microbial consortium}

For the present study, a stable anaerobic dechlorinating microbial consortium $\mathrm{KB}-\mathrm{1}^{\mathrm{TM}}$ (SiREM, Canada) was used as inoculum. This enrichment culture was originally derived from soil and groundwater contaminated with TCE and contains bacteria of the genus Dehalococcoides sp., Geobacter sp., Methanomethylovorans sp. together with a variety of several other organisms (Duhamel and Edwards, 2006). All incubations were conducted in a defined mineral medium as described by Haest et al. (2011), except that the yeast extract concentration was lowered to $10 \mathrm{mg} \mathrm{L}^{-1}$. Cysteine and sodium sulfate was included in the growth medium but was excluded from the experimental medium to limit direct or indirect sulfate sources. This dechlorinating enrichment culture was routinely spiked with TCE (1 $\mathrm{mM}$ aqueous concentration) and sodium formate $(3.5 \mathrm{mM})$ and the liquid phase was purged before each spiking with pure $\mathrm{N}_{2}$ in order to remove any daughter products produced during incubation.

\subsection{Analytical procedures}

Chlorinated ethenes (TCE, DCE isomers and vinyl chloride) were analyzed by gas chromatography (Agilent 6890N, Mass Spectrometry: Agilent 5973) as described by Heimann et al. (2007). A $200 \mu \mathrm{L}$ headspace sample is injected into a $21 \mathrm{ml}$ sample vial containing $0.5 \mathrm{~mL}$ acidified internal standard (10 ppmv aqueous solution of chloroform) and $9.5 \mathrm{~mL}$ of distilled water. The standards and the analytical controls were also treated in the same way as the experimental samples. Detection limits for the chlorinated ethenes were below $1 \mu \mathrm{g} \mathrm{L} \mathrm{L}^{-1}$.

Samples for headspace hydrogen $\left(\mathrm{H}_{2}\right)$ were analyzed immediately with a reduction gas detector (Trace Analytical RGD2) as described elsewhere (Heimann et al., 2006). Gaseous $\mathrm{H}_{2}$ standards were prepared by diluting pure $\mathrm{H}_{2}$ gas in $120 \mathrm{ml}$ serum bottles containing pure nitrogen. In the biotic controls, Vejen and in HFO bottles a concentration that was higher than the detection range of instrument was always observed (also during the last experimental days in HFO treatment), and the sample had to be diluted several times prior to analysis. Standards covered a range of 0.4 to $51.3 \mathrm{ppm}$ by volume. Headspace concentrations were converted to aqueous concentrations and amount of substance per bottle by using Henry's law constants for $\mathrm{H}_{2}$ (Heimann et al., 2006). Error bars on all graphs indicate the standard deviation from the average value of four replicates of batch bottles, if not indicated otherwise.

Samples for organic anions (formate, acetate and lactate) and inorganic anions (sulfate and chloride) were analyzed by suppressed ion chromatography on a Dionex ICE-AS1 ion exclusion column and sulfate samples by Dionex Ion Pac AS14 column (Heimann et al., 2007). 
Total elemental analysis of the chemical extracts was performed by atomic absorption spectroscopy (Perkin Elmer Instruments Analyst 200 AAS 5000) with flame detection at wavelengths of $248.33 \mathrm{~nm}$ and 279.83 for iron and manganese, respectively. Detection limits were below $0.01 \mathrm{mM}$. The $\mathrm{Fe}(\mathrm{II})$ concentration in extracts or in liquid phase was determined using a ferrozine assay where HEPES buffer $(50 \mathrm{mM}, \mathrm{pH} 7.0)$ was used instead of ammonium acetate buffer (Viollier et al., 2000).

\section{Results and discussion}

\subsection{Dynamics of $\mathrm{H}_{2}$ concentrations and terminal electron acceptor processes}

In addition to dechlorination and reduced species, the $\mathrm{H}_{2}$ levels and formate consumption was monitored in all experiments (Fig.1f-j and Fig. 2e-h). Formate served as the major electron donor in all treatments whereas $1.3 \mathrm{mM}$ of acetate was also present in the Grindsted sample. Possible other $\mathrm{H}_{2}$ producing reactions occurring include yeast extract $\left(10 \mathrm{mg} \mathrm{L}^{-1}\right)$ fermentation (0.075 $\mathrm{mmol} \mathrm{H}_{2}$ per liter) and biomass decay (Yang and McCarty, 1998).
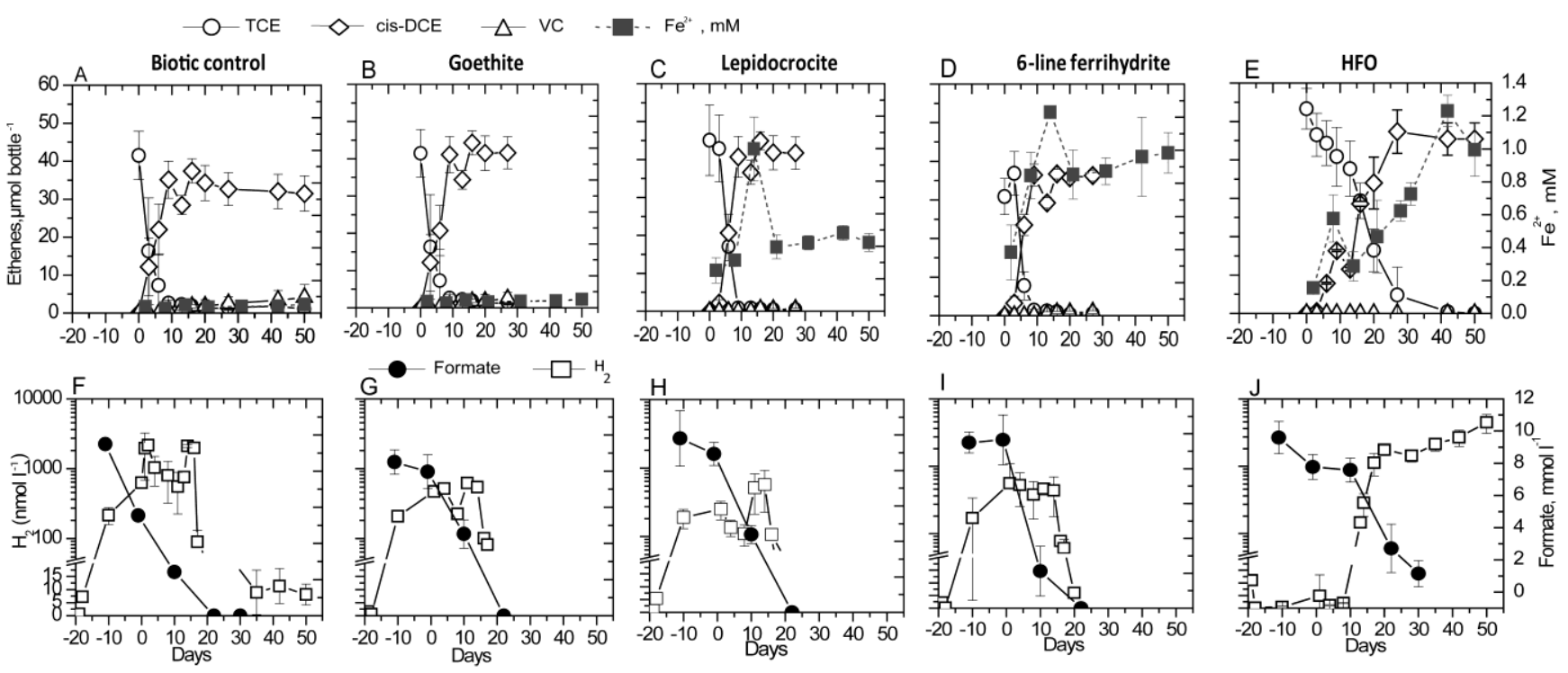

Figure 1. Observed dynamics in chloroethenes, $\mathrm{Fe}^{2+}$, formate and $\mathrm{H}_{2}$ concentration in synthetic Fe minerals containing batch bottles. The chloroethenes concentrations include the concentration in headspace and dissolved ethenes and the values are the averages of four replicates measurements, whereas the error bars indicate the standard deviation. Figures A-E include chlorinated ethenes concentrations [TCE $(-\mathrm{O}-)$, cis-DCE $(\diamond-), \mathrm{VC}(-\Delta-)$ in $\mu \mathrm{mol}^{-1}$ bottle ${ }^{-1}$ and Fe ${ }^{2+}(---)$ in mM plotted against degradation time. Figures from $\mathrm{F}-\mathrm{J}$ represents formate $(--)$ and $\mathrm{H}_{2}\left(-\mathrm{Q}_{-}\right)$concentration in mmol $\mathrm{I}^{-1}$ and nmol $\mathrm{I}^{-1}$ respectively and are plotted against degradation time. No Fe treated as biotic control (A \& F), Goethite (B and G), Lepidocrocite (C and H), 6-Line Ferrihydrite powder (D \& I) and 2-line ferrihydrite suspension / HFO (E and J).

Pre-incubation of batch bottles with formate has been done (indicated in negative days) in order to allow biological and/or chemical oxygen consumption to further deplete residual oxygen prior to the addition of KB-1 and TCE avoiding further changes to the sediment redox environment. This pre-incubation, resulted in a $\mathrm{H}_{2}$ concentration of up to $250 \mathrm{nM}$ in all synthetic Fe treatments except in 6-line ferrihydrite (up to $600 \mathrm{nM}$ ) and in HFO (around 10 $\mathrm{nM}$ ), produced probably due to fermentation reactions by spore forming fermenters. The $\mathrm{H}_{2}$ data in abiotic treatments indicate that these fermenters could survive even after formaldehyde treatment; however the actual reason is unknown (Fig.SI.1b). A complete consumption of formate as well as the acetate in the Grindsted sample was observed before inoculation, implying a lack of reducing equivalents to support microbial dechlorination. Therefore, an extra $3 \mathrm{mM}$ formate was added on the $0^{\text {th }}$ day before the addition of microbial inoculum.

The observed $\mathrm{H}_{2}$ concentrations are much higher than detected in systems depleted in organic substrate and a situation where the supply of $\mathrm{H}_{2}$ is limiting is not obtained as long as 
there is formate present. The reason for this could be that $\mathrm{H}_{2}$ production from formate is thermodynamically very favorable, implying that $\mathrm{H}_{2}$ production produces energy even when high concentrations of $\mathrm{H}_{2}$ are built up. This presumably implies that a large population of formate fermenters can be supported, potentially scavenging the system for other nutrients, possibly limiting the activity of terminal electron acceptors such as dechlorinators or Fe oxide reducers. If this is the explanation, then another substrate for $\mathrm{H}_{2}$ production needs to be used to obtain a system characterized by competition.

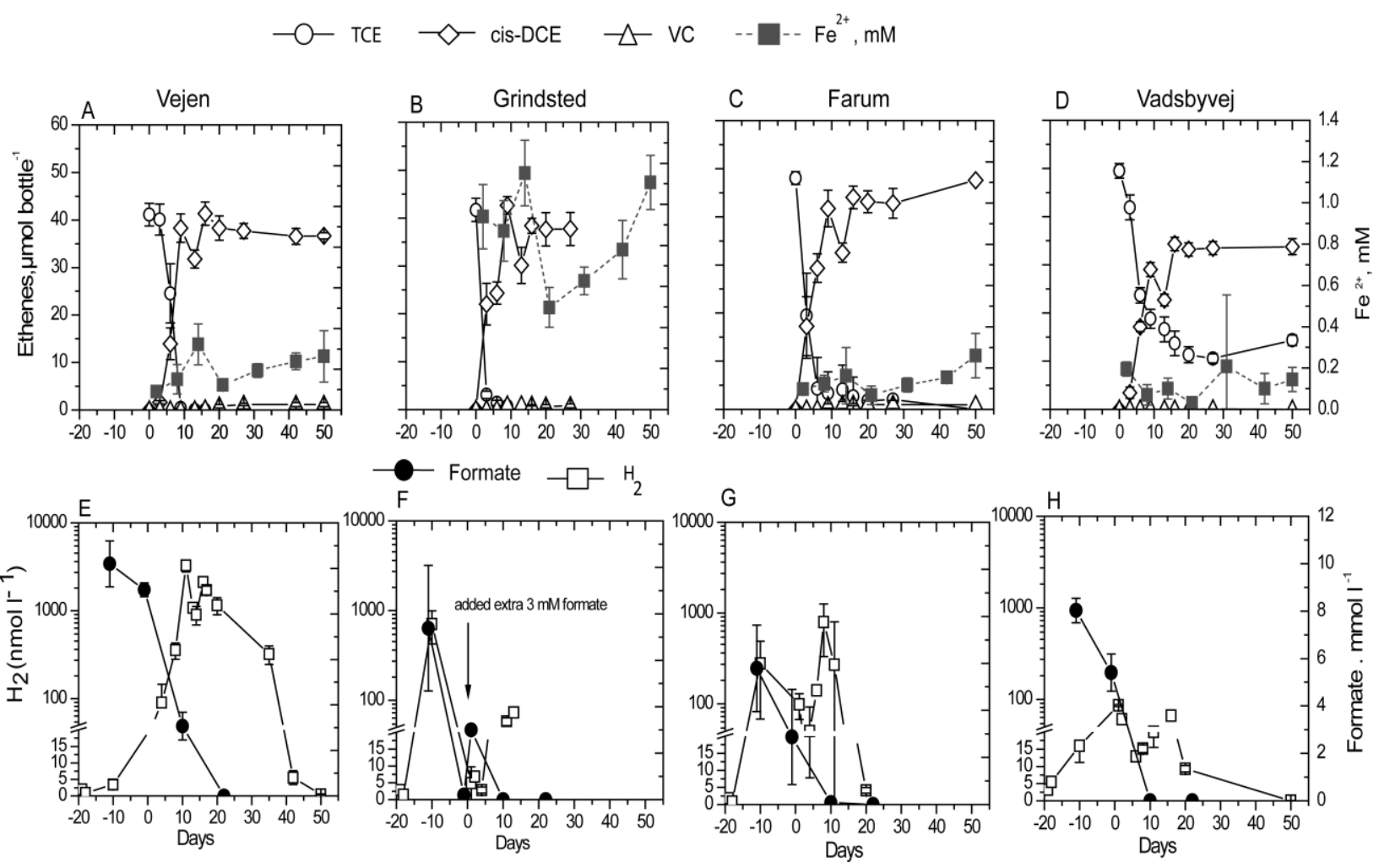

Figure 2. Concentration of chloroethenes, $\mathrm{Fe}^{2+}$, formate and $\mathrm{H}_{2}$ in presence of natural Fe oxides or hydroxides containing sediments. The chloroethenes concentrations include the concentration in headspace and dissolved ethenes and the values are the averages of four replicates measurements whereas the error bars indicate the standard deviation. Figures A-D include chlorinated ethenes concentrations [TCE $(-\mathrm{O}-)$, cis-DCE $(\diamond-), \mathrm{VC}(-\Delta-)$ ] in $\mu \mathrm{mol}^{-}$bottle ${ }^{-1}$ and Fe ${ }^{2+}(----)$ in mM plotted against degradation time. Figures from $\mathrm{E}-\mathrm{H}$ represents formate $(--)$ and $\mathrm{H}_{2}\left(-\mathrm{Q}^{-}\right)$concentration in mmol $\mathrm{I}^{-1}$ and nmol $\mathrm{I}^{-1}$ respectively and are plotted against degradation time. Vejen ( $A$ and $E)$, Grindsted ( $B$ and $F)$, Farum ( $C$ and $G)$ and Vadsbyvej (D and $H)$.

It may also be that the time available compared to the relative growth rates of $\mathrm{H}_{2}$ producers and consumers has not been long enough, however maintaining the system for longer times without running out of one or the other reactant would be complicated. Most of the previous studies conducted for determining $\mathrm{H}_{2}$ thresholds during dechlorination reactions e.g., Lu et al. (2001), Luitjen et al. (2004), Wei and Finneran (2011) utilized a slow-release $\mathrm{H}_{2}$ donor or were measured in ground water systems where electron donor is usually limited. However, the choice of formate has been made after different trials using different electron donors, due to the capability of formate in maintaining the $\mathrm{pH}$ of the medium for a long running experiment of dechlorination where $\mathrm{pH}$ is a very important factor that affects the rate of reaction.

In general, the variations in the $\mathrm{H}_{2}$ concentration reflect the balance between the metabolic activity of fermenters producing $\mathrm{H}_{2}$ (Clostridium sp.) and the $\mathrm{H}_{2}$ consumption by dechlorinators and/or iron and manganese reducers present in the system. The $\mathrm{H}_{2}$ concentrations exceed $1000 \mathrm{nM}$ and suggest that the dechlorination process is not limited due to a too low $\mathrm{H}_{2}$ level (Heimann et al., 2007; Lee et al., 2007). This $\mathrm{H}_{2}$ level also suggests the possibility of additional $\mathrm{H}_{2}$-consuming processes such as 
methanogenesis and acetogenesis along with the observed $\mathrm{Fe}(\mathrm{III})$ and $\mathrm{Mn}$ (IV) reduction in the experimental treatments. The occurrence of these $\mathrm{H}_{2}$-consuming processes was previously shown in similar studies conducted using similar culture and experimental conditions as used in this study (Paul and Smolders, 2014, 2015), implying that the dechlorinators had several competitors for the donated electrons in these systems.

To assess the dynamics in these systems characterized by several concomitant TEAP's we have used the observed concentration data over time to derive rates of the individual redox processes, as well as a rate of $\mathrm{H}_{2}$ consumption based on the dechlorination and rates of $\mathrm{Fe}(\mathrm{II})_{\mathrm{aq}}$ production. The rate of $\mathrm{Fe}$ (II) $)_{\mathrm{aq}}$ production was used here despite of the rate of $\mathrm{Fe}(\mathrm{II})_{\text {tot }}$ production because of the difficulties in the determination of sediment bound $\mathrm{Fe}$ (II) over time from the batch bottles. However, it should be noted that rates of Fe oxide reduction have been higher than those of $\mathrm{Fe}(\mathrm{II})$ aq production. As an overall indicator of the state of the balance between $\mathrm{H}_{2}$ production and consumption we have also derived the $\mathrm{H}_{2}$ residence time. Selected samples are shown in Figure 3 and the detailed representation of all samples is given in the supplementary information (Fig.SI.2a, 2b and 2c).

A general feature to be noted from the data of all samples is the increase in the residence time of $\mathrm{H}_{2}$ when the TCE rate decreases. This observation possibly reflect the transition from TCE to cis-DCE dechlorination where there is still production of $\mathrm{H}_{2}$ which may actually be lower, but the rate at which it is used decreases so much that the residence time increases substantially. However, the duration on which these changes occurred differed between the synthetic and natural samples. The rapid increase in residence time after TCE removal seems to be very similar for all of the synthetic oxides except for HFO. In the biotic control as well as in the natural samples this increase in residence time of $\mathrm{H}_{2}$ did not coincide with the TCE removal.

The more reactive Fe-oxides showed lower peaks in the $\mathrm{H}_{2}$ residence times than the more stable Fe-oxides, reflecting the lower rate of reduction of the more stable $\mathrm{Fe}$-oxides allowing the peak of $\mathrm{H}_{2}$ during the transition to cis-DCE reduction to become higher. The difference in both the width and height of peak in residence time shows a much larger variation among the natural samples with the peak height spanning 2 orders of magnitude.

After the TCE to cis-DCE conversion, residence time of $\mathrm{H}_{2}$ coincides with the rate of $\mathrm{H}_{2}$ consumption which becomes slow at that point perhaps due to the shift in the dominant microbial dechlorination to Fe reducers in the system. The lag time observed in synthetic oxides and biotic control might reflect the time the dechlorinating subpopulation of Geobacter required to activate the systems that are responsible for the Fe-oxide reduction. Geobacter was also responsible for TCE degradation in addition to Dehalococcoides and Clostridium and was the dominant organisms in KB-1 culture. While in the case of natural samples, Fe(III) reduction has taken place prior to incubation with KB-1 culture probably due to indigenous microorganisms. In Grindsted, the indigenous and supplemented formate was depleted very fast leaving the system "unstable" with respect to the iron reduction and dechlorination pattern. There was no general reaction trend observed in those reactions in Grindsted sample which shows that the organic carbon availability plays a role as well for the $\mathrm{H}_{2}$ dynamics. 

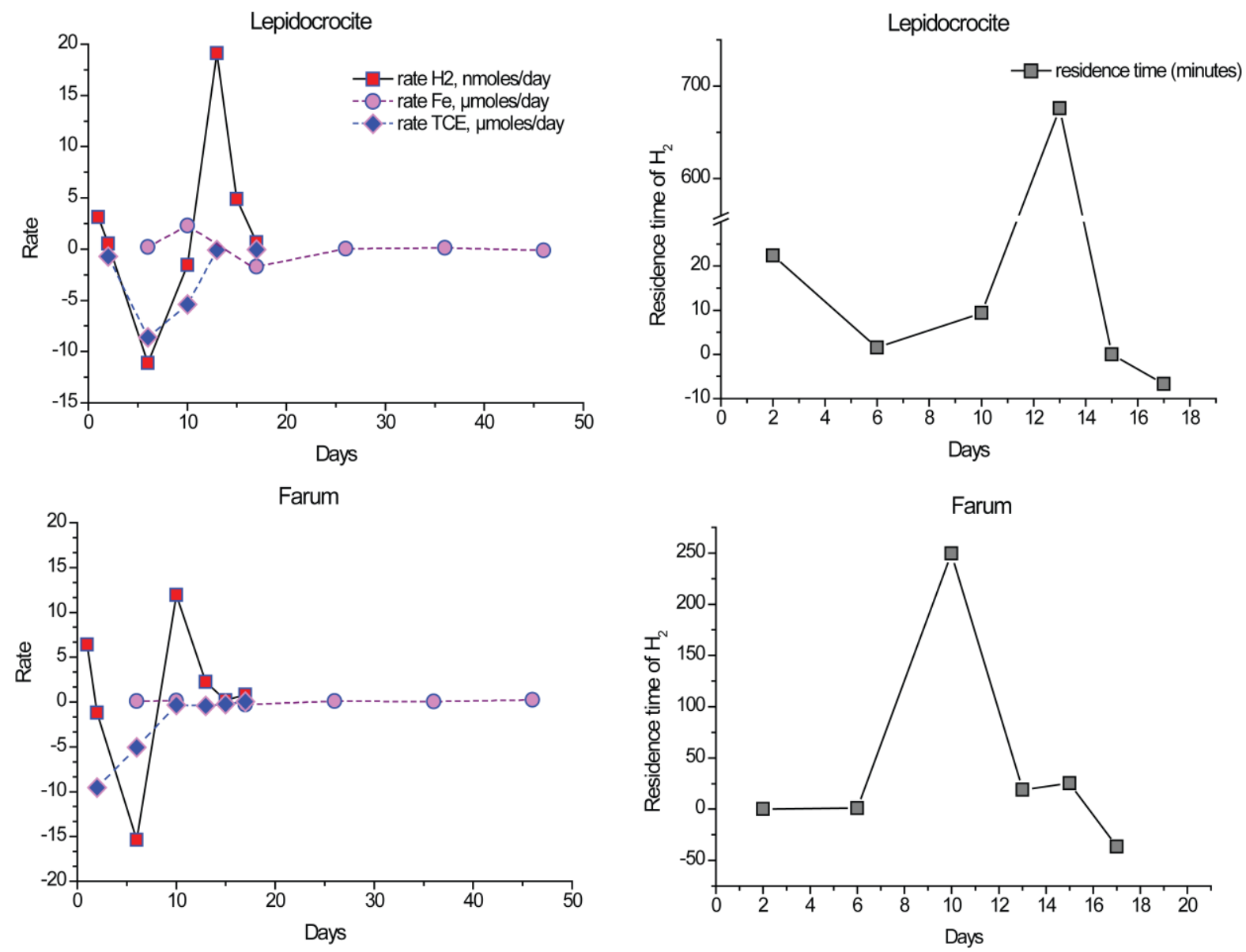

Figure 3. The rates of the individual redox processes per day, as well as a rate of $\mathrm{H}_{2}$ consumption (nmoles per day) based on the dechlorination and rates of Fe(II) aq production (both rates in $\mu$ moles per day) as well as the residence time of $\mathrm{H}_{2}$ plotted against the days of incubation in a synthetic Fe-oxide system (Lepidocrocite) and an environmental sample containing system (Farum). The negative and positive rate of $\mathrm{H}_{2}$ corresponds to the rate of consumption and production, respectively while for the rates of $\mathrm{Fe}(\mathrm{II})_{\mathrm{aq}}$ production, negative values indicate a decrease in the $\mathrm{Fe}^{2+}{ }_{\text {(aq) }}$ production and for TCE reduction, negative values indicate an increase in the TCE to cisDCE dechlorination rate.

\subsection{Relation between $\mathrm{H}_{2}$ levels, dechlorination and terminal electron acceptor processes}

The $\mathrm{H}_{2}$ levels measured in this study were well above the observed concentration ranges in previous studies where a much lower $\mathrm{H}_{2}$ concentration in the range of $0.6-0.9 \mathrm{nM} \mathrm{H}_{2}$ for PCE/TCE dechlorination as well as $0.1-2.0 \mathrm{nM}$ and $0.1-0.4 \mathrm{nM} \mathrm{H}_{2}$ for $\mathrm{Fe}(\mathrm{III})$ and $\mathrm{Mn}$ reduction reactions respectively was measured (Lu et al., 2001). Here, we did not observe distinct $\mathrm{H}_{2}$ levels corresponding to the TCE dechlorination and $\mathrm{Fe}(\mathrm{III})$ succession. The first dechlorination step in all systems was characterized by $\mathrm{H}_{2}$ concentrations far beyond any metabolic threshold or related to partial equilibrium due to rapid formate fermentation producing an excess of reducing equivalents (Heimann et al., 2007). This ample availability of electron donor in all batches is a likely reason for the observed similar dechlorination rates and the lack of a larger time lag in the Fe(III) rich systems. The hydrogen level stabilized at ca. $8 \mathrm{nM}$ in the biotic control during the last days of incubation whereas in other treatments no steady-state hydrogen $\mathrm{H}_{2}$ levels were achieved till the end of this study. This is possibly due to the use of different substrates and electron acceptors and also due to the limited experimental time frame ( $\mathrm{Lu}$ et al., 2001). Hence, the specific steady-state $\mathrm{H}_{2}$ levels as suggested by Lovley and Goodwin (1988) were not observed in this study. Likewise, the 
partial-equilibrium approach where the in situ activities of reactants and products control the occurrence of the different redox processes is also not applicable in this study (Heimann and Jakobsen, 2006; Jakobsen et al., 1998). To examine whether there was any relation between the observed $\mathrm{H}_{2}$ levels and the reduction rates, we have compared the $\mathrm{H}_{2}$ levels associated with the highest reduction rates of both electron acceptors derived from the slopes of the curves in Fig. 1 and 2 (Figure 3). Maximum rate of TCE reductive dechlorination into cisDCE was associated with a $\mathrm{H}_{2}$ concentration of up to $500 \mathrm{nM}$ in all treatments. The highest iron reduction rate was measured at a higher $\mathrm{H}_{2}$ level than those at which TCE dechlorination occurred but the former process spanned the $\mathrm{H}_{2}$ range of TCE reduction, again underlining that both processes can occur concomitantly. It also suggests that TCE to cis-DCE reduction is actually more efficient than the Fe-oxide reduction, so that the pool of $\mathrm{H}_{2}$ is diminished when TCE reduction is active, and grows when Fe-oxide reduction dominates. It appears that the consumption of $\mathrm{H}_{2}$ by dechlorinators is actually capable of lowering the concentration of $\mathrm{H}_{2}$ in the system. Nonetheless, the presence of high donor supply and its rapid fermentation kinetics was not sufficient to exclude Fe(III) reduction and therefore both reactions take place concurrently.

A time lag prior to cis-DCE dechlorination coincided with a large buildup of $\mathrm{H}_{2}$ above 1000 $\mathrm{nM}$ in the biotic control, HFO and Vejen (Fig. 1f and j, 2e), probably accompanied by active methanogenesis. Methanogens are commonly found to be growing concomitantly with Dehalococcoides within chloroethene-degrading communities (Heimann et al., 2007). The $\mathrm{H}_{2}$ concentrations observed in biotic control are also in the range observed for methanogenic conditions. This explanation seems justifiable since Fe(III) availability was limited either due to its absence in the biotic control or depleted due to microbial iron reduction as in the case of Vejen and HFO samples. This result is consistent with observations in similar studies using control sand where $40 \mu \mathrm{mol}$ bottle ${ }^{-1}$ of methane was formed during incubation and scavenged around $82 \%$ of the electron equivalents supplied (Paul and Smolders, 2014, 2015). The fermentation burst upon rapid formate utilization probably favored the enrichment of methanogens (Methanomethylovorans sps.) and they can compete for $\mathrm{H}_{2}$ with dehalogenators (Fennell et al., 1997; Smatlak et al., 1996; Yang and McCarty, 1998).

\subsection{Pattern of TCE degradation in the presence of iron oxides}

No cis-DCE was observed in the abiotic control treatments (Fig.SI.1a). Dechlorination of cisDCE was initiated at a very slow rate in the biotic control during the 50 days of incubation (Fig. 1a). No other treatments showed the onset of cis-DCE dechlorination. Conversely, degradation of TCE into ethene did occur in the source cultures grown in the same anaerobic mineral medium but with cysteine and under the same conditions ( $\mathrm{pH} 7.2$, TCE $1 \mathrm{mM})$ as the experimental set up, illustrating that this potential was present in the inoculum (data not shown).

A complete degradation of TCE to cis-DCE was observed in the presence of synthetic Fe minerals. The degradation time was about 40 days for HFO amended systems (Fig.1e) whereas it took only 10 days for complete conversion of TCE into cis-DCE in biotic control, 2-line ferrihydrite (not shown), goethite, lepidocrocite and 6-line ferrihydrite treatments (Fig.1). The dechlorination pattern in these synthetic Fe minerals results is consistent with the previous batch experiments using similar Fe oxides (Paul et al., 2013).

A fast TCE to cis-DCE dechlorination similar to the biotic control was observed in the environmental sample treatments, except in the Vadsbyvej system (Fig. 2). In the Vadsbyvej sample, after an initial partial TCE dechlorination, a stall in the cis-DCE production occurred (Fig. 2d). The presence of Mn(IV), highest in the Vadsbyvej sample, along with Fe(III) as the alternate competing terminal electron acceptors, could explain this limited TCE reduction. 
The dissolved $\mathrm{Fe}(\mathrm{II})$ measured from the liquid phase was maximally $5 \%$ of the total reduced Fe. Owing to the crystallinity of goethite, there was negligible Fe(III) reduction as seen in Fig. 1b. About $0.2-1.2 \mathrm{mM}$ of dissolved $\mathrm{Fe}^{2+}$ was measured in other synthetic $\mathrm{Fe}$ mineral batches (Fig 1c-e). The adsorbed or precipitated Fe(II) content extracted using $0.5 \mathrm{~N} \mathrm{HCl}$ was comparable to the $5 \mathrm{~N} \mathrm{HCl}$ extractable fraction in all synthetic Fe treatments, but constituted only a small percentage of the total Fe content. Vejen and Grindsted showed the highest percentage of $\mathrm{Fe}$ (III) reduction among the environmental samples whereas it was found for HFO in the synthetic Fe minerals (Table 1).

Approximately half of the $5 \mathrm{~N} \mathrm{HCl}$ extractable $\mathrm{Fe}(\mathrm{II})$ was extracted using $0.5 \mathrm{~N} \mathrm{HCl}$ in all environmental samples, except for the Vadsbyvej sample, where $0.5 \mathrm{~N} \mathrm{HCl}$ gave a much smaller fraction $(4 \%)$ of the $5 \mathrm{~N} \mathrm{HCl}$ extractable content. This is possibly due to the presence of $\mathrm{Fe}$ (II) bearing silicates in this clayey sample and the effective dissolution of these minerals by the much stronger acid extraction. Although the total Fe content of the environmental samples was larger than that of synthetic Fe coated substrates, the fraction of microbially reduced $\mathrm{Fe}$ was similar in both cases. The low concentration of dissolved $\mathrm{Fe}^{2+}$ detected in the environmental samples is possibly due to the presence of clay minerals or layer silicates acting as Fe(II) sink in these samples (Roden and Urrutia, 1999).

In all batch treatments, a change from the initial color of the sediment or Fe oxide into a blackish color has been noticed during the incubation period; however the mineral transformation was not investigated in detail. This color change is possibly due to the formation of mixed $\mathrm{Fe}$ (II)-Fe(III) compounds such as magnetite in HFO system or might likely be a combination of siderite $\left(\mathrm{FeCO}_{3}\right.$, formed with inorganic carbon produced from the oxidation of formate or from $\mathrm{NH}_{4} \mathrm{CO}_{3}$ ) and or mixed $\mathrm{Fe}$ (II)-Fe (III) phases (green rust). The possibility of formation of phosphate containing iron minerals can be neglected in synthetic Fe experiments since the experimental medium contained only a few micromoles per litre of phosphate. However in the case of environmental samples, Fe(III) reduction offers the production of a wide variety of reducing minerals such as iron sulfides, iron oxides, iron carbonates, and mixed oxides such as green rust or magnetite under natural conditions.

These minerals are found to be active dechlorinating minerals, dechlorinates at different rates and are sometimes more reactive than naturally occurring mineral species, potentially due to its greater surface area (Lee and Batchelor, 2002a, 2002b). The adsorption of dissolved $\mathrm{Fe}^{2+}$ onto these mineral surfaces can potentially increase the reactivity of the minerals. In our study, although the formation of secondary minerals is observed, a detailed investigation of those minerals except in the case of magnetite in HFO systems was not made. Magnetite is considered to be a less reactive mineral than other secondary minerals (Lee and Batchelor, 2002a). The contribution of these secondary minerals in dechlorination activity in our systems was difficult to estimate since abiotic and biotic seems to be highly interrelated (biotic reactions produce secondary minerals which results in abiotic reactions) and synergistic $\left(\mathrm{Fe}^{2+}\right.$ promotes the activity of secondary minerals) and appears to be more complex than biologically mediated pathways.

Moreover, it is often observed that the primary reaction products from the reduction of chlorinated ethenes as acetylenes without the accumulation of daughter products. Further work is needed to disentangle abiotic reaction pathways due to secondary minerals from biotic reactions and also the interaction between biotic and abiotic reactions. The Fe mineral transformation occurs due to recrystallization in the presence of $\mathrm{Fe}^{2+}$ and even ferrous iron also plays a major role in abiotic degradation that microbes play in reductive dechlorination, at rates comparable to biological processes. The resulting secondary mineral can only be partially extracted using $5 \mathrm{~N} \mathrm{HCl}$. This effect is even more pronounced for the weaker $0.5 \mathrm{~N}$ 
$\mathrm{HCl}$ extraction which is less efficient as extraction medium for magnetite (Heron et al., 1994). This mineral transformation and the high resistivity of the transformed products towards weak acid extractants might explain the difference of up to $20 \%$ of the difference between $5 \mathrm{~N} \mathrm{HCl}$ extractable $\mathrm{Fe}$ fraction before and after the microbial reduction. The removal of $\mathrm{Fe}$ and $\mathrm{Mn}$ through the liquid sampling over time as well as the removal of liquid phase for adsorbed $\mathrm{Fe}$ (II) determination after reduction experiment explains the loss of up to 10 percent.

The dechlorination pattern observed in synthetic and environmental samples showed that iron(III) reduction occur concomitantly with dechlorination and thus these electron acceptors compete for $\mathrm{H}_{2}$ (AFCEE, 2004; Aulenta et al., 2007; Dupont et al., 2003; Paul et al., 2013; Wiedemeier et al., 1998; Yager et al., 1997). When the dechlorination reaction began, sufficient electron donor was present and TCE to cis-DCE dechlorination occurred together with $\mathrm{Fe}(\mathrm{III})$ reduction. Dechlorination reactions constituted only $30 \%$ of electrons equivalents supplied while majority (up to 96\%) of electrons flows towards $\mathrm{Fe}(\mathrm{III})$ reduction in $\mathrm{Fe}$ enriched systems. Thus, simultaneous occurrence of both electron consuming reactions ultimately resulted in lack of electron donor in these systems and as such, further dechlorination was not possible.

Electron flow up to 20-85\% towards iron reduction was observed in other studies (Azizian et al., 2008; Azizian et al., 2010; Malaguerra et al., 2011; Paul et al., 2013). A previous study by Sleep et al. (2005) also observed cis-DCE as the terminal end product of PCE dechlorination under electron donor limited conditions. Another possible explanation for the pronounced effect of iron reduction on cis-DCE dechlorination would be the competition for $\mathrm{H}_{2}$ between Dehalococcoides sp. and iron reducers for which $\mathrm{H}_{2}$ is the ultimate electron donor. It is already shown that the cis-DCE dechlorinating microorganisms probably have higher $\mathrm{H}_{2}$ thresholds than iron reducers (Lu et al., 2001; Luijten et al., 2004).

Iron reduction may have reduced the $\mathrm{H}_{2}$ levels below the thresholds required for cis-DCE and VC reduction resulting in an accumulation of cis-DCE (Evans and Koenigsberg, 2001). In the biotic control, even without any Fe addition, the cis-DCE stall was probably due to the occurrence of methanogenesis which resulted in a high methane production as explained in section 2.2. Previous studies (Paul and Smolders, 2014, 2015) conducted using the same materials and subculture at the same experimental conditions confirmed this explanation. This methane production was the result of sudden outburst of fermentation reactions from the fast-fermenting organic carbon substrate used (formate) and in turn competitively consumed around $82 \%$ of the total electron supplied while in HFO; a very low amount of methane was detected.

The absence or very low methane in HFO is due to the inhibitory effect of Fe (III) on methanogenic populations i.e., Fe(III) reducers are generally assumed to out-compete methanogens because of their higher affinity for hydrogen at low concentrations. In contrast to this study, a complete dechlorination of TCE to ethene with simultaneous iron reduction process is observed by Wei and Finneran (2011) and Azizian et al. (2008), as the donor was a slow-fermenting substrate and was provided in excess. Thus, the extent and ultimate effect of the competition on the outcome of the dechlorination may also depend on the amount and type of electron donor compared to the amount of alternative TEA's.

\subsection{Manganese reduction and manganese species in subsurface samples}

Manganese was only detectable in the natural samples as shown in Table 1. Vejen and Vadsbyvej samples contain the highest initial Mn content. About $80 \%$ of the $0.5 \mathrm{~N} \mathrm{HCl}$ 
extractable Mn was found in the dissolved phase of Vejen sample whereas only about 5-16\% in other samples (data not shown). Despite the lowest initial Mn concentration in the Grindsted and Farum samples, a higher percentage of it appeared to be reducible as determined by $0.5 \mathrm{~N} \mathrm{HCl}$ extractions (assumed to extract only the easily extractable $\mathrm{Mn}$ species). Electron mass balance calculations indicate that about 2-18\% of the total electron equivalents supplied was channeled to Mn reduction. Although, this percentage of electron consumption appeared to be smaller when compared to the Fe(III) oxides in competition with TCE, the higher oxidation potential of Mn-oxides implies that TCE dechlorination can be significantly affected in natural sediment systems containing significant amount of Mn as alternative terminal electron acceptor.

\section{Conclusions}

The electron flux in the systems was limited by the electron accepting pathway in all set ups except in 2-line ferrihydrite suspension rather than the $\mathrm{H}_{2}$ production rate which was not limited. The type and the high donor level used in this study implies that the systems cannot be considered in a state of partial equilibrium and accordingly, the concomitant occurrence of TEAPs with a broad range of energy yields, is possible. It appears that the $\mathrm{H}_{2}$ level, rather than being controlled by thermodynamics, is controlled by the differences in the efficiencies of the $\mathrm{H}_{2}$ producers and the $\mathrm{H}_{2}$ consumers. The use of a slow- $\mathrm{H}_{2}$ yielding substrates in contrast to formate which is a high rate $\mathrm{H}_{2}$ yielding substrate may possibly yield systems that are closer to partial equilibrium and may be necessary to selectively enhance dechlorination while managing competition reactions. This study illustrates parallel consumption of electrons by TCE dechlorination, $\mathrm{Fe}(\mathrm{III})$ or $\mathrm{Mn}(\mathrm{IV})$ reduction and methanogenesis. Only a fraction of the electron flow was used for dechlorination.

The simultaneous occurrence of different terminal electron accepting processes shows that the distinction between dechlorination and other microbial reduction processes based on $\mathrm{H}_{2}$ concentrations alone is not feasible. The higher $\mathrm{H}_{2}$ thresholds for the reduction of lower chlorinated compounds (cis-DCE, VC) than for TCE and the strict requirement of $\mathrm{H}_{2}$ as electron donor for Dehalococcoides sps. suggest that there is competition between cis-DCE reduction and $\mathrm{Fe}(\mathrm{III})$ reduction for $\mathrm{H}_{2}$, even with formate as electron donor. However this competition effect needs to be investigated through further studies. Studies specifically aimed at the effects of $\mathrm{Mn}(\mathrm{IV})$-reduction is also recommended to further investigate the effect of Mn reduction on TCE dechlorination.

\section{Funding and acknowledgments}

This project was conducted as part of the Marie Curie exchange programme in the initial training network GOODWATER ITN within the European Community's Seventh Framework Programme [FP7-PEOPLE-2007-1-1-ITN] under Marie Curie Grant Agreement Number 212683. We acknowledge SiREM, Guelph, Canada for kindly providing the KB-1 culture used for this study. We also acknowledge Jens Schaarup Sørensen for helping with the GC-MS analysis and Mona Refstrup for assistance in setting up the anaerobic experiments.

\section{REFERENCES}

AFCEE, 2004. Principles and practices of enhanced anaerobic bioremediation of chlorinated solvents. In: Leeson A, Beevar E, Henry B, Fortenberry J, Coyle C, editors. DTIC Document. 
Albrechtsen HJ, Bjerg PL, Ludvigsen L, Rügge K, Christensen TH. 1999. An anaerobic field injection experiment in a landfill leachate plume, Grindsted, Denmark 2. Deduction of anaerobic (methanogenic, sulfate-, and Fe(III)-reducing) redox conditions. Water Resour Res 35:1247-1256.

Andersen T, Vikjær Lassen EVH. 1990. Ionbytning i danske sandjorde, Laboratoriet for Teknisk Hygiejne Danmarks Tekniske Højskole, Lyngby.

Aulenta F, Pera A, Rossetti S, Petrangeli Papini M, Majone M. 2007. Relevance of side reactions in anaerobic reductive dechlorination microcosms amended with different electron donors. Water Res 41:27-38.

Azizian MF, Behrens S, Sabalowsky A, Dolan ME, Spormann AM, Semprini L. 2008. Continuous-flow column study of reductive dehalogenation of PCE upon bioaugmentation with the Evanite enrichment culture. J Contam Hydrol 100:11-21.

Azizian, M.F., Marshall, I.P.G., Behrens, S., Spormann, A.M., Semprini, L., 2010. Comparison of lactate, formate, and propionate as hydrogen donors for the reductive dehalogenation of trichloroethene in a continuousflow column. J Contam Hydrol 113:77-92.

Bjerg PL, Christensen TH. 1992. Spatial and temporal small-scale variation in groundwater quality of a shallow sandy aquifer. J Hydrol 131:133-149.

Bjerg PL, Ruegge K, Pedersen JK, Christensen TH. 1995. Distribution of redox-sensitive groundwater quality parameters downgradient of a landfill (Grindsted, Denmark). Environ Sci Technol 29:1387-1394.

Bradley PM. 2003. History and Ecology of Chloroethene Biodegradation: A Review. Biorem J 7:81-109.

Chambon JC, Bjerg PL, Scheutz C, Bælum J, Jakobsen R, Binning P.J. 2013. Review of reactive kinetic models describing reductive dechlorination of chlorinated ethenes in soil and groundwater. Biotechnol Bioeng 110:1-23.

Chapelle FH, Haack SK, Adriaens P, Henry MA, Bradley PM. 1996. Comparison of Eh and $\mathrm{H}_{2}$ measurements for delineating redox processes in a contaminated aquifer. Environ Sci Technol 30:3565-3569.

Damgaard I, Bjerg PL, Bælum J, Scheutz C, Hunkeler D, Jacobsen CS, Tuxen N, Broholm MM. 2013. Identification of chlorinated solvents degradation zones in clay till by high resolution chemical, microbial and compound specific isotope analysis. J Contam Hydrol 146:37-50.

Duhamel M, Edwards EA, 2006. Microbial composition of chlorinated ethene-degrading cultures dominated by Dehalococcoides. FEMS Microbiol Ecol 58:538-549.

Dupont RR, Sorensen DL, McLean JE, Doucette BJ, Loucks M. 2003. Enhancement of trichloroethylene degradation via carbon donor and microbial amendment addition In: Magar VS, Kelley ME, editors. Seventh International In Situ and On-Site Bioremediation Symposium, . Part A. Bioremediation of Halogenated Compounds., Orlando, Florida, USA, 2-5 June 2003.

Evans PJ, Koenigsberg SS. 2001. A bioavailable ferric iron assay and relevance to reductive dechlorination., Sixth international in situ and on site bioremediation symposium.San Diego, CA.

Fennell DE, Gossett JM, Zinder SH. 1997. Comparison of butyric acid, ethanol, lactic acid, and propionic acid as hydrogen donors for the reductive dechlorination of tetrachloroethene. Environ Sci Technol 31:918-926. 
Gossett JM. 1987. Measurement of Henry's law constants for $\mathrm{C}_{1}$ and $\mathrm{C}_{2}$ chlorinated hydrocarbons. Environ Sci Technol 21:202-208.

Haest PJ, Philips J, Springael D, Smolders E. 2011. The reactive transport of trichloroethene is influenced by residence time and microbial numbers. J Contam Hydrol 119:89-98.

Heimann A, Jakobsen R, Blodau C. 2009. Energetic constraints on $\mathrm{H}_{2}$-dependent terminal electron accepting processes in anoxic environments: a review of observations and model approaches. Environ Sci Technol 44:2433.

Heimann AC, Batstone DJ, Jakobsen R. 2006. Methanosarcina spp. drive vinyl chloride dechlorination via interspecies hydrogen transfer. Appl Environ Microbiol 72:2942-2949.

Heimann AC, Friis AK, Scheutz C, Jakobsen R. 2007. Dynamics of reductive TCE dechlorination in two distinct $\mathrm{H}_{2}$ supply scenarios and at various temperatures. Biodegradation 18:167-179.

Heimann AC, Jakobsen R. 2006. Experimental evidence for a lack of thermodynamic control on hydrogen concentrations during anaerobic degradation of chlorinated ethenes. Environ Sci Technol 40:3501-3507.

Heron G, Bjerg PL, Gravesen P, Ludvigsen L, Christensen TH. 1998. Geology and sediment geochemistry of a landfill leachate contaminated aquifer (Grindsted, Denmark). J Contam Hydrol 29:301-317.

Heron G, Crouzet C, Bourg ACM, Christensen TH. 1994. Speciation of Fe(II) and Fe(III) in contaminated aquifer sediments using chemical extraction techniques. Environ Sci Technol 28:1698-1705.

Hoehler TM, Alperin MJ, Albert DB, Martens CS. 1998. Thermodynamic control on hydrogen concentrations in anoxic sediments. Geochim Cosmochim Acta 62:1745-1756.

Hunkeler D, Abe Y, Broholm MM, Jeannottat S, Westergaard C, Jacobsen CS, Aravena R, Bjerg PL. 2011. Assessing chlorinated ethene degradation in a large scale contaminant plume by dual carbon-chlorine isotope analysis and quantitative PCR. J Contam Hydrol 119:69-79.

Jakobsen R, Albrechtsen HJ, Rasmussen M, Bay H, Bjerg PL, Christensen TH. 1998. $\mathrm{H}_{2}$ concentrations in a landfill leachate plume (Grindsted, Denmark): In situ energetics of terminal electron acceptor processes. Environ Sci Technol 32:2142-2148.

Lee W, Batchelor B. 2002a. Abiotic reductive dechlorination of chlorinated ethylenes by iron-bearing soil minerals. 1. Pyrite and magnetite. Environ Sci Technol 36:5147-5154.

Lee W, Batchelor B. 2002b. Abiotic reductive dechlorination of chlorinated ethylenes by iron-bearing soil minerals. 2. Green rust. Environ Sci Technol 36:5348-5354.

Lee I-S, Bae J-H, McCarty PL. 2007. Comparison between acetate and hydrogen as electron donors and implications for the reductive dehalogenation of PCE and TCE. J Contam Hydrol 94:76-85.

Löffler FE, Tiedje JM, Sanford RA. 1999. Fraction of electrons consumed in electron acceptor reduction and hydrogen thresholds as indicators of halorespiratory physiology. Appl Environ Microbiol 65:4049-4056. 
Lovley DR, Goodwin S. 1988. Hydrogen concentrations as an indicator of the predominant terminal electronaccepting reactions in aquatic sediments. Geochim Cosmochim Acta 52:2993-3003.

Lovley DR, Phillips EJP. 1986. Organic matter mineralization with reduction of ferric iron in anaerobic sediments. Appl Environ Microbiol 51:683-689.

Lu DX-X, Tao S, Bosma T, Gerritse J. 2001. Characteristic hydrogen concentrations for various redox processes in batch study. J Environ Sci Health, Part A: Environ Sci Eng 36:1725-1734.

Luijten MLGC, Roelofsen W, Langenhoff AAM, Schraa G, Stams AJM. 2004. Hydrogen threshold concentrations in pure cultures of halorespiring bacteria and at a site polluted with chlorinated ethenes. Environ Microbiol 6:646-650.

Malaguerra F, Chambon JC, Bjerg PL, Scheutz C, Binning PJ. 2011. Development and sensitivity analysis of a fully kinetic model of sequential reductive dechlorination in groundwater. Environ Sci Technol 45:8395-8402.

Maymo-Gatell X, Chien Y-t, Gossett JM, Zinder SH. 1997. Isolation of a bacterium that reductively dechlorinates tetrachloroethene to ethene. Science 276:1568-1571.

Mazur CS, Jones WJ, Tebes-Stevens C. 2003. $\mathrm{H}_{2}$ consumption during the microbial reductive dehalogenation of chlorinated phenols and tetrachloroethene. Biodegradation 14:285-295.

Paul L, Smolders E. 2015. Bioenhanced dissolution of dense non-aqueous phase of trichloroethylene as affected by iron reducing conditions: Model systems and environmental samples. Chemosphere 119:1113-1119.

Paul L, Smolders E. 2014. Inhibition of iron(III) minerals and acidification on the reductive dechlorination of trichloroethylene. Chemosphere 111:471-477.

Paul L, Herrmann S, Koch CB, Philips J, Smolders E. 2013. Inhibition of microbial trichloroethylene dechlorination by $\mathrm{Fe}(\mathrm{III})$ reduction depends on $\mathrm{Fe}$ mineralogy: a batch study using the bioaugmentation culture KB-1. Water Res 47:2543-2554.

Pedersen JK, Bjerg PL, Christensen TH. 1991. Correlation of nitrate profiles with groundwater and sediment characteristics in a shallow sandy aquifer. J Hydrol 124:263-277.

Postma D, Jakobsen R. 1996. Redox zonation: Equilibrium constraints on the $\mathrm{Fe}(\mathrm{III}) / \mathrm{SO}_{4}$-reduction interface. Geochim Cosmochim Acta 60:3169-3175.

Roden EE, Urrutia MM. 1999. Ferrous iron removal promotes microbial reduction of crystalline iron(III) oxides. Environ Sci Technol 33:1847-1853.

Schwertmann U, Cornell RM. 2000. Iron Oxides in the Laboratory: Preparation and characterization $2^{\text {nd }}$ edition. Weinheim, Germany: Wiley-VCH Verlag GmbH.

Sleep BE, Brown AJ, Lollar BS. 2005. Long-term tetrachlorethene degradation sustained by endogenous cell decay. J Environ Eng Sci 4:11-17. 
Smatlak CR, Gossett JM, Zinder SH. 1996. Comparative kinetics of hydrogen utilization for reductive dechlorination of tetrachloroethene and methanogenesis in an anaerobic enrichment culture. Environ Sci Technol 30:2850-2858.

Viollier E, Inglett PW, Hunter K, Roychoudhury AN, Van Cappellen P. 2000. The ferrozine method revisited: $\mathrm{Fe}(\mathrm{II}) / \mathrm{Fe}(\mathrm{III})$ determination in natural waters. Appl Geochem 15:785-790.

Wei N, Finneran KT. 2011. Influence of ferric iron on complete dechlorination of trichloroethylene (TCE) to ethene: Fe(III) reduction does not always inhibit complete dechlorination. Environ Sci Technol 45:7422-7430.

Wiedemeier TH, Swanson M, Moutoux D, Gordon EK, Wilson J, Wilson B, Kampbell D, Haas P, Miller R, Hansen J. 1998. Technical protocol for evaluating natural attenuation of chlorinated solvents in ground water. National Risk Management Research Laboratory, Office of Research and Development, US Environmental Protection Agency Cincinnati, OH.

Yager RM, Bilotta SE, Mann CL, Madsen EL. 1997. Metabolic adaptation and in situ attenuation of chlorinated ethenes by naturally occurring microorganisms in a fractured dolomite aquifer near Niagara falls, New York. Environ Sci Technol 31:3138-3147.

Yang Y, McCarty PL. 1998. Competition for hydrogen within a chlorinated solvent dehalogenating anaerobic mixed culture. Environ Sci Technol 32:3591-3597. 


\section{Supplementary information}

Reductive dechlorination of trichloroethylene (TCE) in competition with Fe and Mn oxides - observed dynamics in $\mathrm{H}_{2}$-dependent terminal electron accepting processes

Laiby Paul $^{1}$, Rasmus Jakobsen ${ }^{3}$, Erik Smolders ${ }^{1}$, Hans-Jørgen Albrechtsen ${ }^{2}$, Poul L. Bjerg ${ }^{2} *$

${ }^{1}$ Division of Soil and Water Management, KU Leuven, Kasteelpark Arenberg, B-3000 Leuven, Belgium

${ }^{2}$ Department of Environmental Engineering, Miljoevej, Building 113, Technical University of Denmark, DK-2800 Lyngby, Denmark

${ }^{3}$ Geochemical Department, GEUS, Øster Voldgade 10, 1350 Copenhagen K, Denmark

No: of pages-7 (including cover page)

No: of Figures-5

*Correspondence to: Poul L. Bjerg, Department of Environmental Science and Engineering, Miljoevej, Building 113, Technical University of Denmark, DK-2800, Lyngby, Denmark; Phone: +45 452516 15; Fax: +45 459328 50; Email: plb@env.dtu.dk

\section{Anaerobic mineral medium}

This medium composition was previously used by Haest et al. (2011) and was originally adapted from Gerritse et al. (1997). The inoculum for the batch degradation experiment was grown on $1 \mathrm{mM} \mathrm{TCE}$ and $3.5 \mathrm{mM}$ formate at $20{ }^{\circ} \mathrm{C}$ in an anaerobic mineral medium containing: $10 \mu \mathrm{M}\left(\mathrm{NH}_{4}\right) \mathrm{H}_{2} \mathrm{PO}_{4}, 0.2 \mathrm{mM} \mathrm{Na} \mathrm{SO}_{4}, 2.9 \mathrm{mM}\left(\mathrm{NH}_{4}\right) \mathrm{HCO}_{3}, 30 \mathrm{mM} 3-(\mathrm{N}-$ morpholino)propanesulfonic acid (MOPS, pKa = 7.21), $11.9 \mathrm{mM} \mathrm{NaOH}, 0.1 \mathrm{mM} \mathrm{KOH}, 1.2$ $\mathrm{mM} \mathrm{Ca}(\mathrm{OH})_{2}, 0.3 \mathrm{mM} \mathrm{MgO}, 10 \mathrm{mg} \mathrm{L}-1$ yeast extract, $1 \mathrm{mM}$ cysteine (not included in the experimental medium), $1 \%$ resazurin, $1 \mathrm{~mL} \cdot \mathrm{L}^{-1}$ trace element stock solution and $1 \mathrm{~mL} \mathrm{~L}{ }^{-1}$ vitamin stock solution.

The trace element stock solution contained $0.5 \mathrm{~g} \mathrm{~L}^{-1}$ EDTA, $2 \mathrm{~g} \mathrm{~L}^{-1} \mathrm{FeSO}_{4} \cdot 7 \mathrm{H}_{2} \mathrm{O}, 0.03 \mathrm{~g} \cdot \mathrm{L}^{-1}$ $\mathrm{MnCl}_{2} .4 \mathrm{H}_{2} \mathrm{O}, 0.13 \mathrm{~g} \mathrm{~L}^{-1} \mathrm{CaCl}_{2} .2 \mathrm{H}_{2} \mathrm{O}, 0.02 \mathrm{~g} \mathrm{~L}^{-1} \mathrm{NiCl}_{2} .6 \mathrm{H}_{2} \mathrm{O}, 0.03 \mathrm{~g} \mathrm{~L}^{-1} \mathrm{Na}_{2} \mathrm{SeO}_{3} .5 \mathrm{H}_{2} \mathrm{O}, 0.1$ $\mathrm{g} \mathrm{L}^{-1} \mathrm{ZnSO}_{4} .7 \mathrm{H}_{2} \mathrm{O}, 0.3 \mathrm{~g} \mathrm{~L}^{-1} \mathrm{H}_{3} \mathrm{BO}_{3}, 0.01 \mathrm{~g} \mathrm{~L}^{-1} \mathrm{CuCl}_{2} .2 \mathrm{H}_{2} \mathrm{O}, 0.03 \mathrm{~g} \mathrm{~L}^{-1} \mathrm{Na}_{2} \mathrm{MoO}_{4}, 0.033 \mathrm{~g} \mathrm{~L}^{-1}$ $\mathrm{Na}_{2} \mathrm{WO}_{4} \cdot 2 \mathrm{H}_{2} \mathrm{O}, 0.2 \mathrm{~g} \mathrm{~L}^{-1} \mathrm{CoCl}_{2} \cdot 6 \mathrm{H}_{2} \mathrm{O}, 0.01 \mathrm{~g} \mathrm{~L}^{-1} \mathrm{AlCl}_{3} \cdot 6 \mathrm{H}_{2} \mathrm{O}$ and $1 \mathrm{~mL} \mathrm{~L}^{-1} \mathrm{HCl}(37 \%)$ (Gerritse et al., 1992). The vitamin stock solution contained $100 \mathrm{mg} \mathrm{L}^{-1} p$-aminobenzoic acid, $50 \mathrm{mg} \mathrm{L}^{-1}$ folic acid, $100 \mathrm{mg} \mathrm{L}^{-1}$ lipoic acid, $100 \mathrm{mg} \mathrm{L}^{-1}$ riboflavic acid, $200 \mathrm{mg} \mathrm{L}^{-1}$ thiamine, $200 \mathrm{mg} \mathrm{L}^{-1}$ nicotic acid, $500 \mathrm{mg} \mathrm{L}^{-1}$ pyridoxamine, $100 \mathrm{mg} \mathrm{L}^{-1}$ pantotheic acid, $100 \mathrm{mg} \mathrm{L}^{-}$ ${ }^{1}$ cobalamine and $20 \mathrm{mg} \mathrm{L}^{-1}$ biotine (Heijthuijsen and Hansen, 1986). 


\section{Figure 1a}

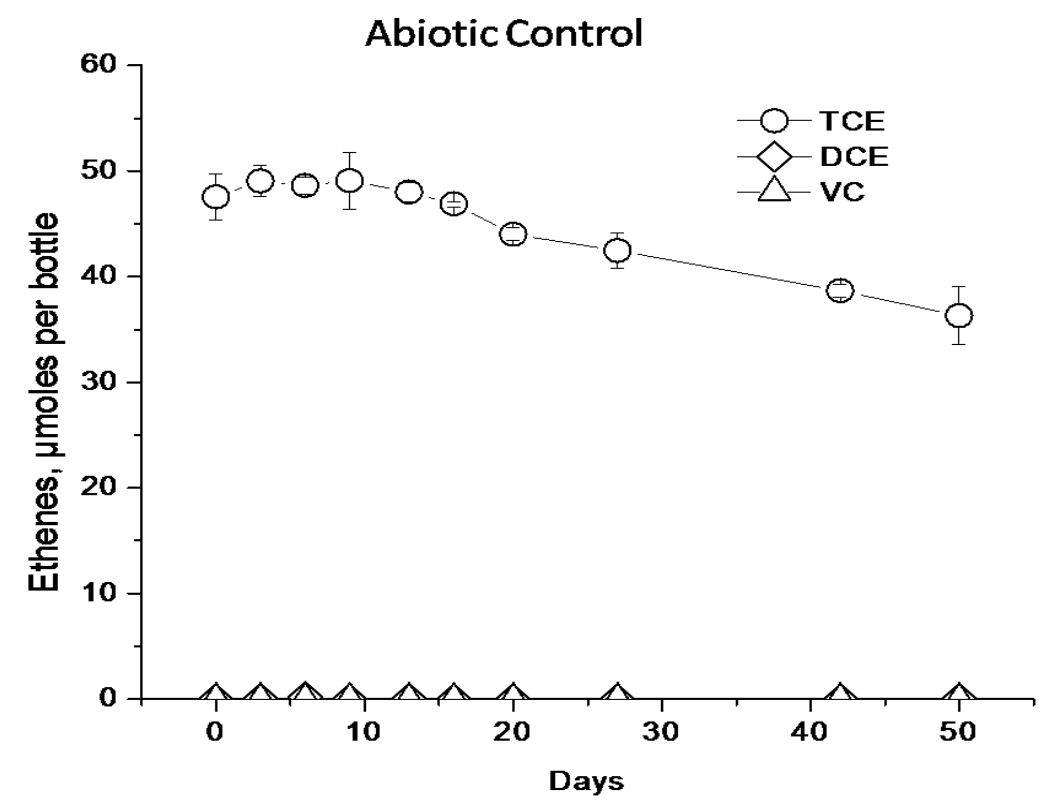

Figure 1b

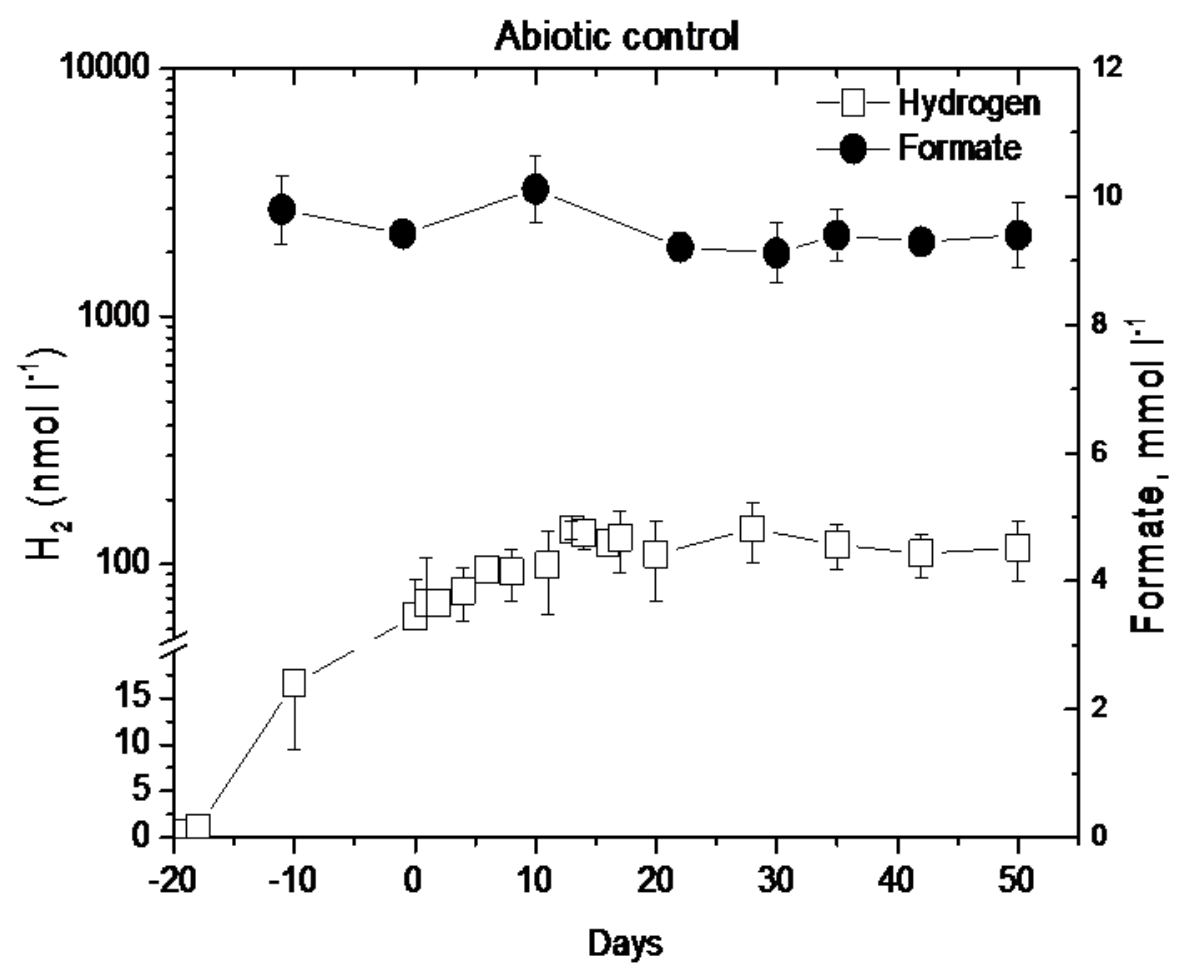

Figure SI. 1 Observed dynamics in chloroethenes, formate and $\mathrm{H}_{2}$ concentration in sterile abiotic controls. The chloroethenes concentrations include the concentration in headspace and dissolved ethenes and the values are the averages of four replicates measurements whereas the error bars indicate the standard deviation. Figure 1a include chlorinated ethenes concentrations [TCE $\left(-\odot_{-}\right)$, cis-DCE $(\diamond)$, VC $(\triangle)$ ] in $\mu$ mol bottle ${ }^{-1}$ plotted against degradation time and figure $1 \mathrm{~b}$ represents formate $(-\bullet)$ and $\mathrm{H}_{2}(\square-)$ concentration in mmol $\mathrm{l}^{-1}$ and nmol $\mathrm{l}^{-1}$ respectively plotted against degradation time. 
Figure 2a
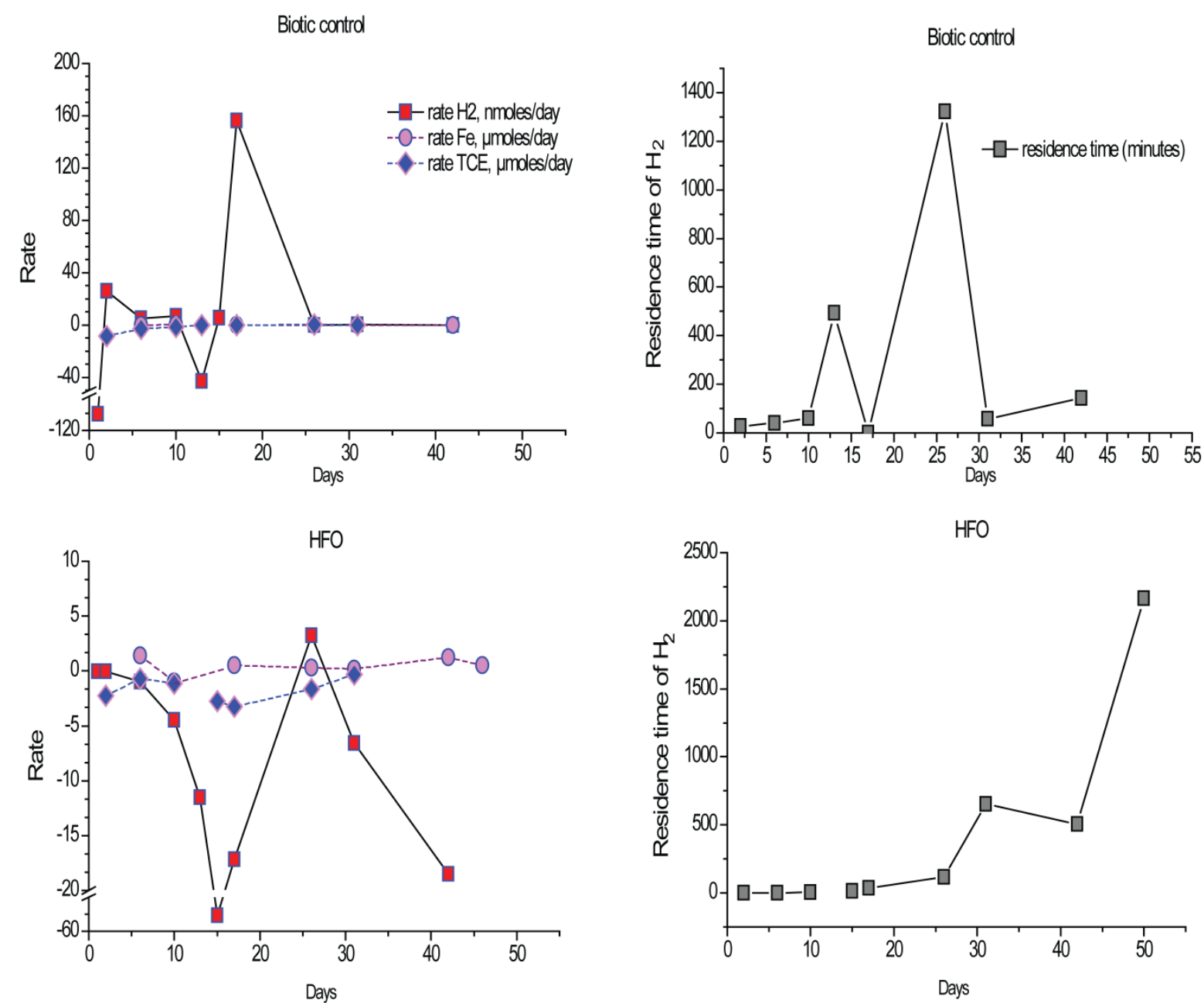

Figure SI. 2a The rates of the individual redox processes per day, as well as a rate of $\mathrm{H}_{2}$ consumption (nmoles per day) based on the dechlorination and $\mathrm{Fe}$-oxide reduction rates (both rates in $\mu$ moles per day) as well as the residence time of $\mathrm{H}_{2}$ plotted against the days of incubation in biotic control and ferrihydrite (HFO) system. The negative and positive rate of $\mathrm{H}_{2}$ corresponds to the rate of consumption and production, respectively while for the rate of $\mathrm{Fe}$-oxide reduction, negative values indicate a decrease in the $\mathrm{Fe}^{2+}$ production and for TCE reduction, negative values indicate an increase in the TCE to cis-DCE dechlorination rate. 
Figure 2b
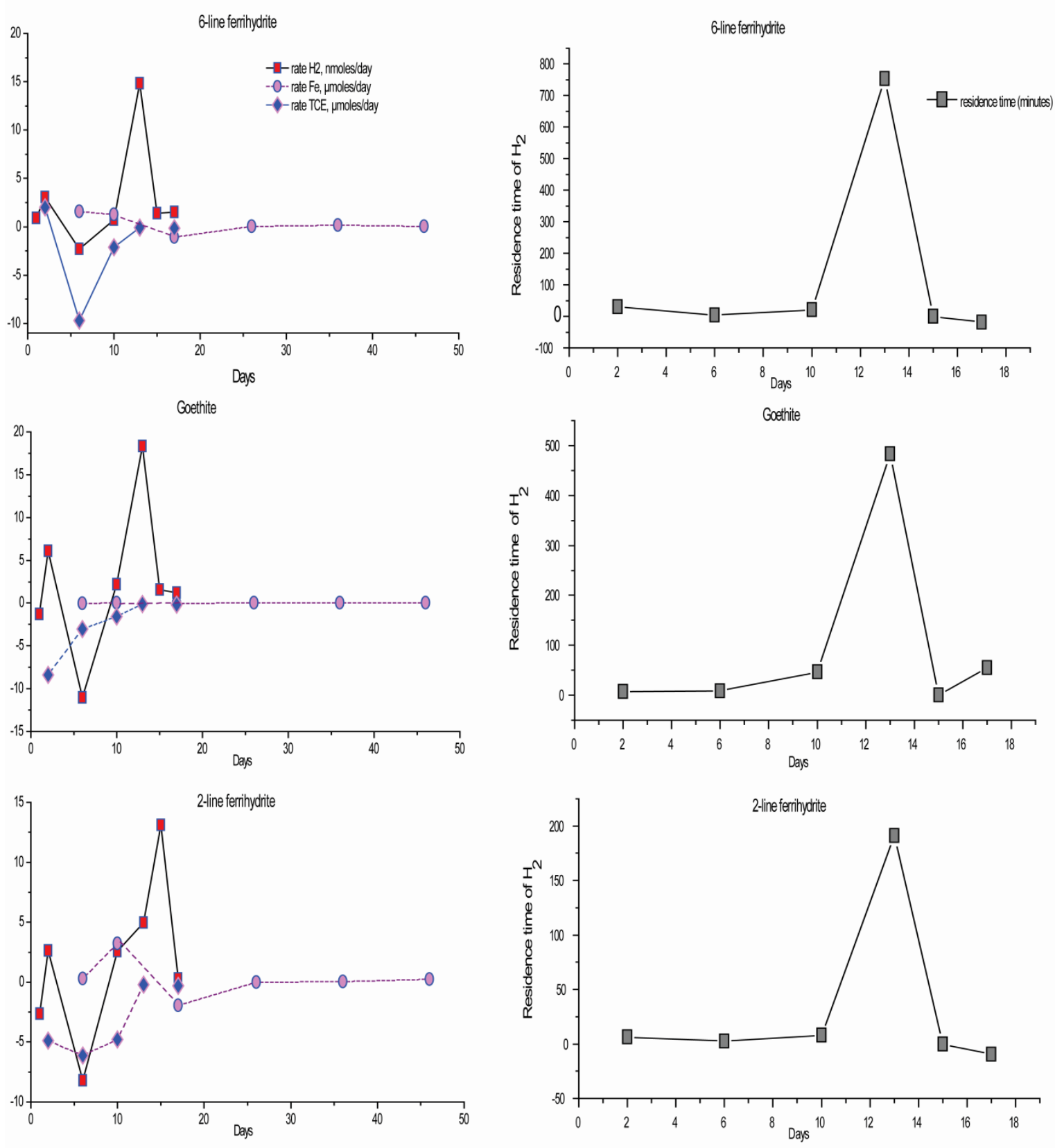

Figure SI. 2b The rates of the individual redox processes per day, as well as a rate of $\mathrm{H}_{2}$ consumption (nmoles per day) based on the dechlorination and $\mathrm{Fe}$-oxide reduction rates (both rates in $\mu$ moles per day) as well as the residence time of $\mathrm{H}_{2}$ plotted against the days of incubation in 6-line ferrihydrite, goethite and 2-line ferrihydrite systems. The negative and positive rate of $\mathrm{H}_{2}$ corresponds to the rate of consumption and production, respectively while for the rate of $\mathrm{Fe}$-oxide reduction, negative values indicate a decrease in the $\mathrm{Fe}^{2+}$ production and for TCE reduction, negative values indicate an increase in the TCE to cis-DCE dechlorination rate. 
Figure 2c
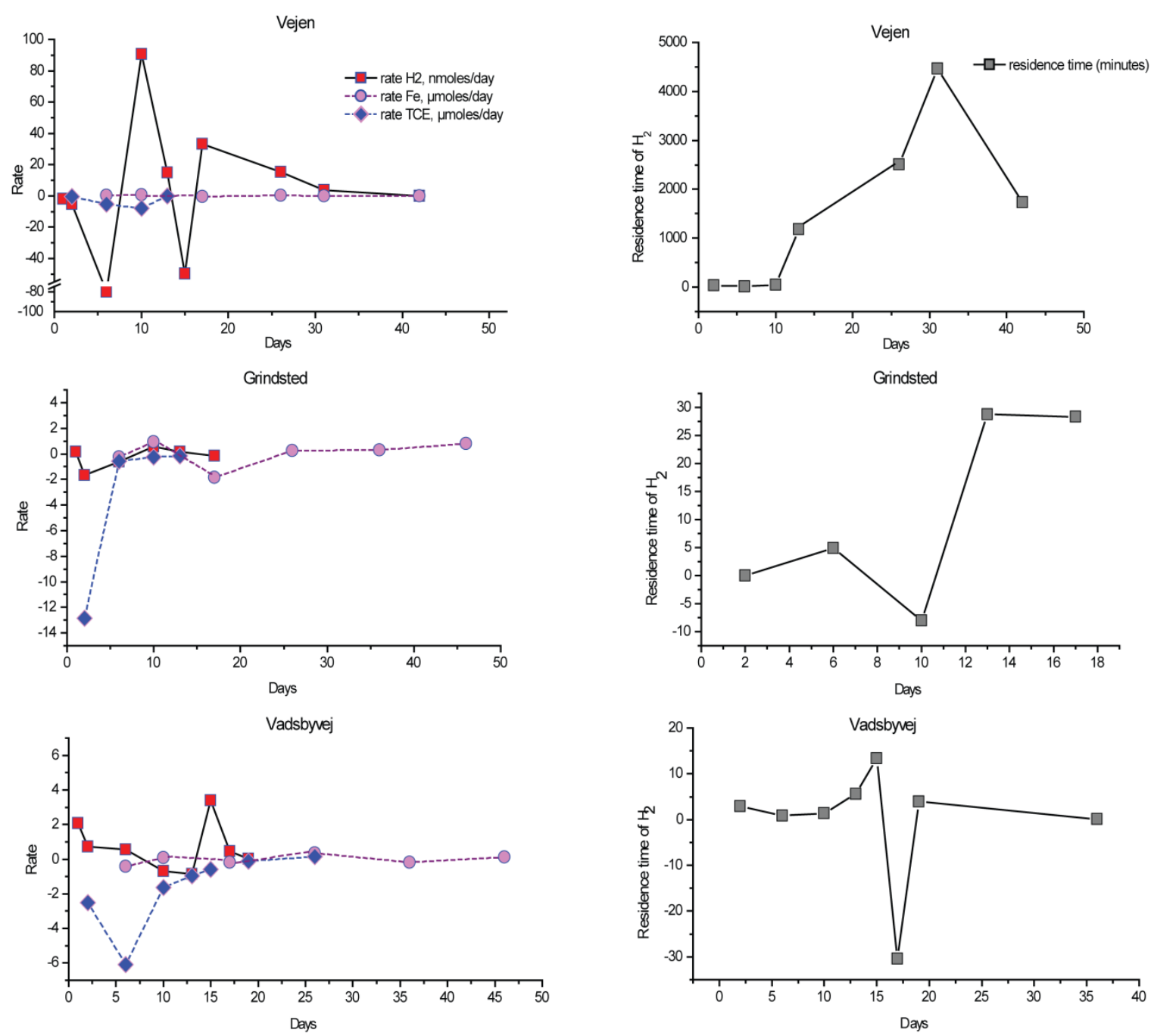

Figure SI.2c The rates of the individual redox processes per day, as well as a rate of $\mathrm{H}_{2}$ consumption (nmoles per day) based on the dechlorination and Fe-oxide reduction rates (both rates in $\mu$ moles per day) as well as the residence time of $\mathrm{H}_{2}$ plotted against the days of incubation in the environmental samples (Vejen, Grindsted and Vadsbyvej). The negative and positive rate of $\mathrm{H}_{2}$ corresponds to the rate of consumption and production, respectively while for the rate of $\mathrm{Fe}$-oxide reduction, negative values indicate a decrease in the $\mathrm{Fe}^{2+}$ production and for TCE reduction, negative values indicate an increase in the TCE to cis-DCE dechlorination rate. 


\section{References}

Gerritse J, Kloetstra G, Borger A, Dalstra G, Alphenaar A, Gottschal J. 1997. Complete degradation of tetrachloroethene in coupled anoxic and oxicchemostats. Applied Microbiology Biotechnology 48: 553-562.

Gerritse J, van der Woude BJ, Gottscha JC. 1992. Specific removal of chlorine from the ortho-position of halogenated benzoic acids by reductive dechlorination in anaerobic enrichment cultures. FEMS Microbiology Letters 100: 273-280.

Haest PJ, Philips J, Springael D, Smolders E. 2011. The reactive transport of trichloroethene is influenced by residence time and microbial numbers. Journal of Contaminant Hydrology 119: 89-98.

Heijthuijsen J, Hansen T. 1986. Interspecies hydrogen transfer in co-cultures of methanolutilizing acidogens and sulfate-reducing or methanogenic bacteria. FEMS Microbiology Letters 38: 57-64. 